\title{
Equatorial insolation: from precession harmonics to eccentricity frequencies*
}

\author{
A. Berger ${ }^{1}$, M. F. Loutre ${ }^{1}$, and J. L. Mélice ${ }^{2}$ \\ ${ }^{1}$ Université catholique de Louvain, Institut d'Astronomie et de Géophysique G. Lemaître, 2 Chemin du Cyclotron, 1348 \\ Louvain-la-Neuve, Belgium \\ ${ }^{2}$ Institut de Recherche pour le Développement, Department of Oceanography, University of Cape Town, Rondebosch 7701, \\ South Africa \\ *Invited contribution by A. Berger, EGS Milutin Milankovic Medal winner 1994
}

Received: 22 June 2006 - Published in Clim. Past Discuss.: 24 July 2006

Revised: 5 October 2006 - Accepted: 5 October 2006 - Published: 12 October 2006

\begin{abstract}
Since the paper by Hays et al. (1976), spectral analyses of climate proxy records provide substantial evidence that a fraction of the climatic variance is driven by insolation changes in the frequency ranges of obliquity and precession variations. However, it is the variance components centered near $100 \mathrm{kyr}$ which dominate most Upper Pleistocene climatic records, although the amount of insolation perturbation at the eccentricity driven periods close to 100-kyr (mainly the $95 \mathrm{kyr}$ - and $123 \mathrm{kyr}$-periods) is much too small to cause directly a climate change of ice-age amplitude. Many attempts to find an explanation to this 100-kyr cycle in climatic records have been made over the last decades. Here we show that the double maximum which characterizes the daily irradiation received in tropical latitudes over the course of the year is at the origin in equatorial insolation of not only strong $95 \mathrm{kyr}$ and $123 \mathrm{kyr}$ periods related to eccentricity, but also of a 11-kyr and a 5.5-kyr periods related to precession.
\end{abstract}

\section{Introduction}

The tropics have been long neglected by paleoclimatologists who mostly followed the hypothesis by Murphy (1876), later independently popularized by Milankovitch (1941), that the driver of the long-term climatic variations is summer in the high northern polar latitudes. For these authors, the progressive build-up of ice sheets requires indeed primarily cool summers in high latitudes, in order to prevent winter snow to melt. But under these conditions, northern latitudes winters are receiving more energy. For example, let us see what has happened at Marine isotopic Stage 5d (MIS-5d) and at MIS-5e in high polar latitudes as compared to low latitudes

Correspondence to: A. Berger

(berger@astr.ucl.ac.be) at the summer solstice. $114 \mathrm{kyr}$ ago, $70^{\circ} \mathrm{N}$ in June received $97 \mathrm{Wm}^{-2}$ less than $126 \mathrm{kyr}$ ago and the equator in December $63 \mathrm{Wm}^{-2}$ more (insolation values from Berger, 1978). This is representing respectively a relative decrease of $18 \%$ at $70^{\circ} \mathrm{N}$ and a relative increase of about the same amount at the equator. This leads to more evaporation in the equatorial regions, a larger latitudinal gradient in the northern hemisphere (remember that if we consider the winter hemisphere, the maximum of the energy received from the Sun is at the equator), a more active transport to the north and possibly more precipitation in polar latitudes. When extended to winter precipitation, the Milankovitch hypothesis is therefore also involving the equatorial and intertropical regions. Much new paleoclimate information indicates that these regions are indeed more important than previously thought. They seem to play an important role in the glacial-interglacial cycles and even in the warming of the last 50 years (see Kerr, 2001, 2003, for a few references).

In this paper, we show an additional reason to emphasize that the equatorial and intertropical regions can play an important role in the response of the climate system to the astronomical forcing. This reason is the presence of significant 123-kyr, 95-kyr, 11-kyr and 5.5-kyr cycles in the amplitude of the seasonal cycle of the energy that the equatorial (and to a lesser extend the intertropical) regions receive from the Sun, cycles directly related to eccentricity and harmonics of precession.

\section{Insolation at the Equator}

In contrast with the extra-tropical latitudes, which exhibits a simple maximum of insolation each year, the Sun comes overhead twice a year at each latitude in the intertropical belt. In particular at the equator, the Sun culminates at the

Published by Copernicus GmbH on behalf of the European Geosciences Union. 


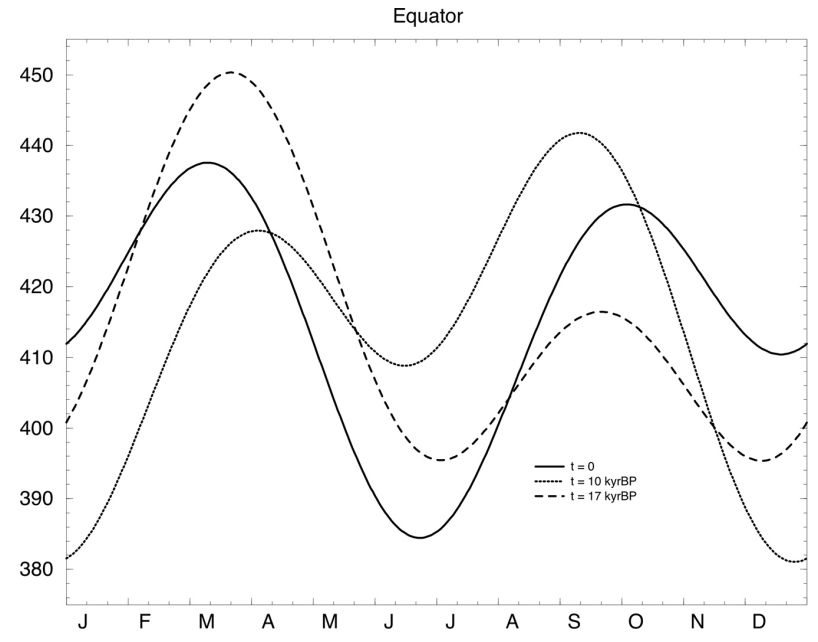

Fig. 1. Seasonal cycle of insolation at the equator at present (full line), at $10 \mathrm{kyr} \mathrm{BP}$ (dotted line) and at $17 \mathrm{kyr}$ BP (dashed line). Units are $\mathrm{Wm}^{-2}$.

zenith at both equinoxes. From classical insolation formula (e.g. Berger et al., 1993) the 24-h mean irradiance at the equator for a given day is given by:

$\bar{W}_{e q}=\frac{S_{a}}{\pi}\left(\frac{1+e \cos (\lambda-\omega)}{1-e^{2}}\right)^{2} \cos \delta$

$S_{a}$ is the amount of solar energy received by unit of time on a surface of unit area perpendicular to the Sun rays and situated at the distance $a$ from the Sun. $a$ is the semi-major axis of the Earth's elliptical orbit around the Sun. It is an invariant in celestial mechanics contrary to the so-called solar constant $S_{0}$, which is defined at the mean distance $r_{m}$ from the Earth to the Sun. On an energy point of view, $r_{m}$ is given by $r_{m}^{2}=a^{2} \sqrt{1-e^{2}}$ where $e$ is the eccentricity of the Earth's orbit. $r_{m}$ and therefore $S_{0}$ are varying with $e$ as:

$S_{0}=\frac{S_{a}}{\sqrt{1-e^{2}}}$

In our calculations of the astronomically driven insolation, the energy output from the Sun is assumed to remain constant over the last millions of years and therefore $S_{a}$ is a constant taken to be $1368 \mathrm{Wm}^{-2}$. In Bard and Frank (2006), this solar constant is shown to vary from 1363 to $1368 \mathrm{Wm}^{-2}$. A constant value of $1365 \mathrm{Wm}^{-2}$ is suggested by the Paleoclimate Modelling Intercomparison Project (PMIP, phase 2) and is used in various modeling studies. The observed value during the last decades was slightly higher, but latest publications concluded that solar activity during the last decades was exceptionally high compared to the previous centuries (Fröhlich and Lean, 2004) and even millennia (Solanki et al., 2004).

- The declination $\delta$ is related to the true longitude of the Sun by

$$
\sin \delta=\sin \lambda \sin \varepsilon
$$

Absolute maximum of mean irradiance

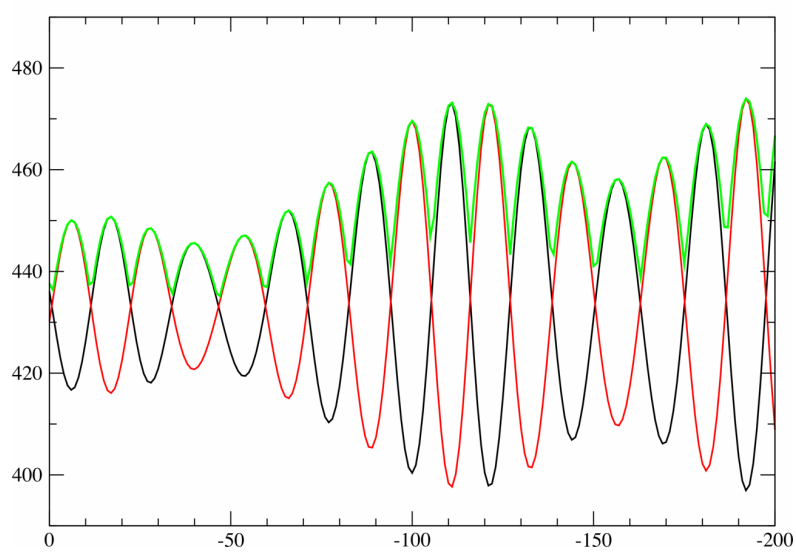

Fig. 2. Time evolution over the last $200 \mathrm{kyr}$ of the 24-h mean irradiance at the equator at spring equinox (black curve) and at autumn equinox (red curve). The time evolution of the maximum of these two series is drawn in green. Units are $\mathrm{Wm}^{-2}$.

$\varepsilon$ being the obliquity and $\lambda$ identifying the calendar days.

- $\omega$ is the longitude of the perihelion. Its numerical value is obtained by adding $180^{\circ}$ to the values calculated from Berger (1978) (see Berger et al., 1993, for more explanations).

- The distance from the Earth to the Sun, $r, \delta$ and $\lambda$ are assumed to be constant over one day.

From Eq. (1), the energy received at the equinoxes $(\delta=0$; $\lambda=0$ for the spring equinox, SE, or $\lambda=\pi$, for the fall equinox, FE) and solstices ( $\delta=\varepsilon$ or $\lambda=\frac{\pi}{2}$ for summer solstice, SS and $\delta=-\varepsilon$ or $\lambda=\frac{3 \pi}{2}$ for winter solstice, WS) can be calculated.

For the present-day with $e=0.0167, \omega=282^{\circ}$ and $\varepsilon=23^{\circ} 27^{\prime}, \mathrm{SE}=439 \mathrm{Wm}^{-2}, \mathrm{SS}=387 \mathrm{Wm}^{-2}, \mathrm{FE}=433 \mathrm{Wm}^{-2}$ and WS $=413 \mathrm{Wm}^{-2}$ leading to a seasonal contrast of $52 \mathrm{Wm}^{-2}$ (SE-SS). Because of precession, the insolation at SE will alternatively be higher and lower than at FE (see Fig. 1). The same holds for the insolation at SS and WS. However, strictly speaking, the insolation values at SE and FE on one hand, and at SS and WS on the other hand, do not provide the absolute maxima and minima over the year. Indeed, these extrema do not occur exactly at the equinoxes and solstices because the Earth-Sun distance modulates the effect of $\delta$ in the course of the year.

Fortunately however, the error made by assuming that the maximum is occurring at one of the equinoxes (Fig. 2) and the minimum (Fig. 3) at one of the solstices remains small. For example, assuming that the summer solstice occurs at the perihelion maximizes the energy received at that particular time. At $198 \mathrm{kyr} \mathrm{BP}, \omega \simeq 90^{\circ}$ and the absolute maximum arises in August (with $451 \mathrm{Wm}^{-2}$ ), but is only $13 \mathrm{Wm}^{-2}$ 
Absolute minimum of mean irradiance

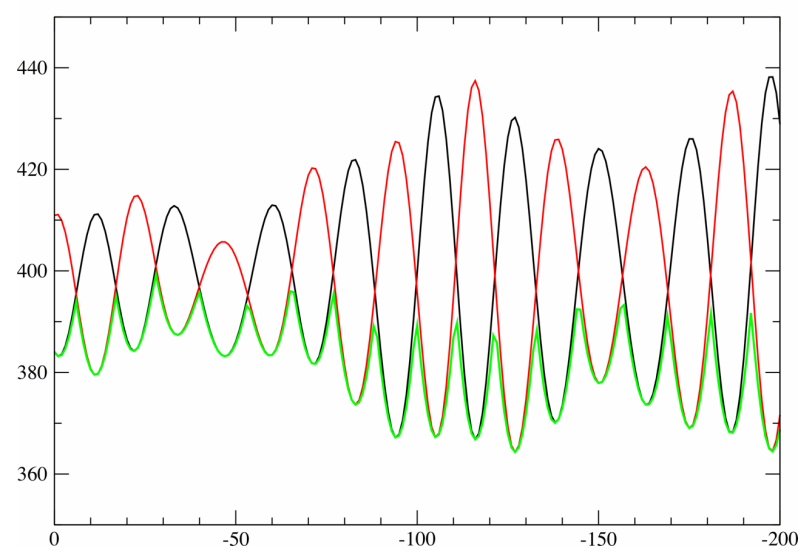

Fig. 3. Time evolution over the last $200 \mathrm{kyr}$ of the 24 -h mean irradiance at the equator at summer solstice (black curve) and at winter solstice (red curve). The time evolution of the minimum of these two series is drawn in green. Units are $\mathrm{Wm}^{-2}$.

larger than the insolation at the fall equinox $\left(438 \mathrm{Wm}^{-2}\right)$. This means that the error assuming that the maximum occurs at $\mathrm{FE}$ is less than $3 \%$. As the minimum is actually at WS $\left(364 \mathrm{Wm}^{-2}\right)$, the real seasonal difference amounts to $87 \mathrm{Wm}^{-2}$, instead of $74 \mathrm{Wm}^{-2}$ if FE-WS is used. Although the error on the seasonal difference reaches $15 \%$, it does not affect the spectral characteristics of the long-term variations of this seasonal difference calculated between the maximum and the minimum values. So for an analytical calculation we will assume that the maximum is occurring at the equinoxes (SE, spring, or FE, fall) and the minimum at the solstices (SS, summer, or WS, winter).

If we assume $e$ and $\varepsilon$ constant over a precessional period, it is easy to see that:

$\mathrm{SE}$ is maximum for $-90^{\circ} \leq \omega \leq 90^{\circ}$

$\mathrm{FE}$ is maximum for $90^{\circ} \leq \omega \leq 270^{\circ}$

SS is minimum for $180^{\circ} \leq \omega \leq 360^{\circ}$

WS is minimum for $\quad 0^{\circ} \leq \omega \leq 180^{\circ}$

In these conditions, the seasonal contrast measured by $\Delta=\operatorname{Max}(\mathrm{SE}, \mathrm{FE})-\min (\mathrm{SS}, \mathrm{WS})$ (Fig. 4) is equal to:

$$
\begin{aligned}
& \text { SE-WS for } 0^{\circ} \leq \omega \leq 90^{\circ} \\
& \text { FE-WS for } 90^{\circ} \leq \omega \leq 180^{\circ} \\
& \text { FE-SS for } 180^{\circ} \leq \omega \leq 270^{\circ} \\
& \text { SE-SS for } 270^{\circ} \leq \omega \leq 360^{\circ}
\end{aligned}
$$

(Let us recall that the perihelion coincides with the spring equinox for $\omega=0^{\circ}$, with the summer solstice for $\omega=90^{\circ}$, with the fall equinox for $\omega=180^{\circ}$ and with the winter solstice for $\omega=270^{\circ}$ ).

This is again an approximation because the insolation at the equinoxes and solstices are also functions of $e$ and $\varepsilon$.

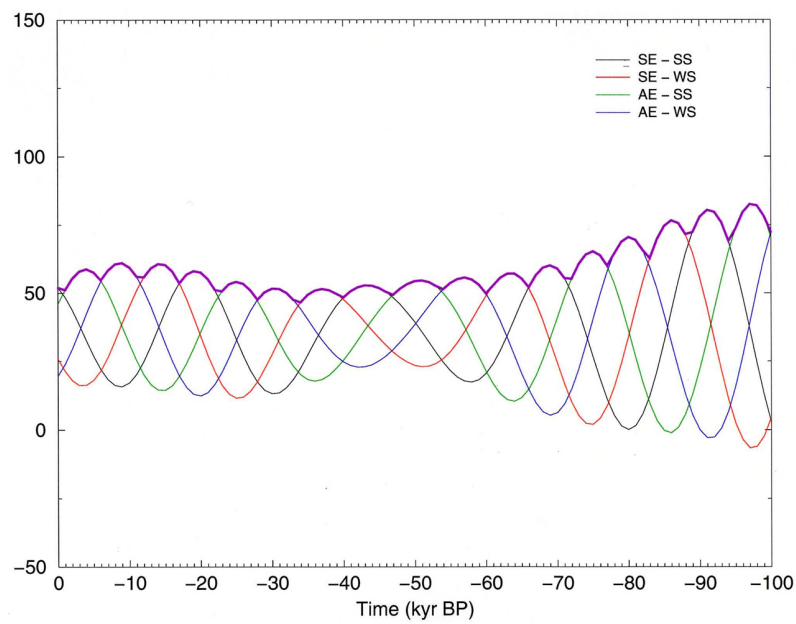

Fig. 4. Time evolution over the last $100 \mathrm{kyr}$ of the amplitude of the 24-h mean irradiance at the equator between spring equinox and summer solstice (black), spring equinox and winter solstice (red), autumn equinox and summer solstice (green) and autumn equinox and winter solstice (blue), and the largest amplitude in the seasonal cycle (purple). Units are $\mathrm{Wm}^{-2}$.

This approximation is actually used to allow an easy analytical range of $\omega$ values to be calculated (in reality, the boundaries of these ranges are not constant in time, varying slightly around $0,90,180$ and $270^{\circ}$ ). However, calculations over the last and next million years show that $\Delta$ is practically equivalent to the real seasonal amplitude of insolation at the equator.

The most striking feature of Fig. 5 (top panel), reproducing the long term variations of $\Delta$ over the last $1 \mathrm{Myr}$ is the significant eccentricity cycles (both the 100 and the 400-kyr) dominating its long-term variations. In addition, a clear and significant 5-kyr period is present with large amplitudes $\left(\sim 10 \mathrm{Wm}^{-2}\right)$ for large values of $e$ and small ones for low values of $e$. The explanation of the high frequency variability finds an origin similar to the half-precession cycle discussed in Berger and Loutre (1997). It was indeed stressed that, although the insolation at the equinoxes follows the climatic precession pattern, the existence of a double maximum at the equator offers the possibility of generating a half-precession cycle $(\sim 11 \mathrm{kyr})$ if the climate system is supposed to respond to the largest value of the two. This is clearly seen in Figs. 2 and 3. If now, the largest seasonal amplitude, $\Delta$, is supposed to drive the climate system behaviour, the two maxima and the two minima are involved. $\Delta(=\operatorname{Max}(\mathrm{SE}, \mathrm{FE})-\min (\mathrm{SS}, \mathrm{WS}))$ is therefore equal to the largest value of the four following parameters: SEWS, FE-WS, FE-SS, SE-SS (Fig. 4). This means that, according to Eqs (4 and 5), a one-fourth-precession cycle is generated. This high frequency signal has an amplitude of the order of a few $\mathrm{Wm}^{-2}$, but it is carried by a signal of much larger amplitude (a few tens of $\mathrm{Wm}^{-2}$ ). Moreover, it must 

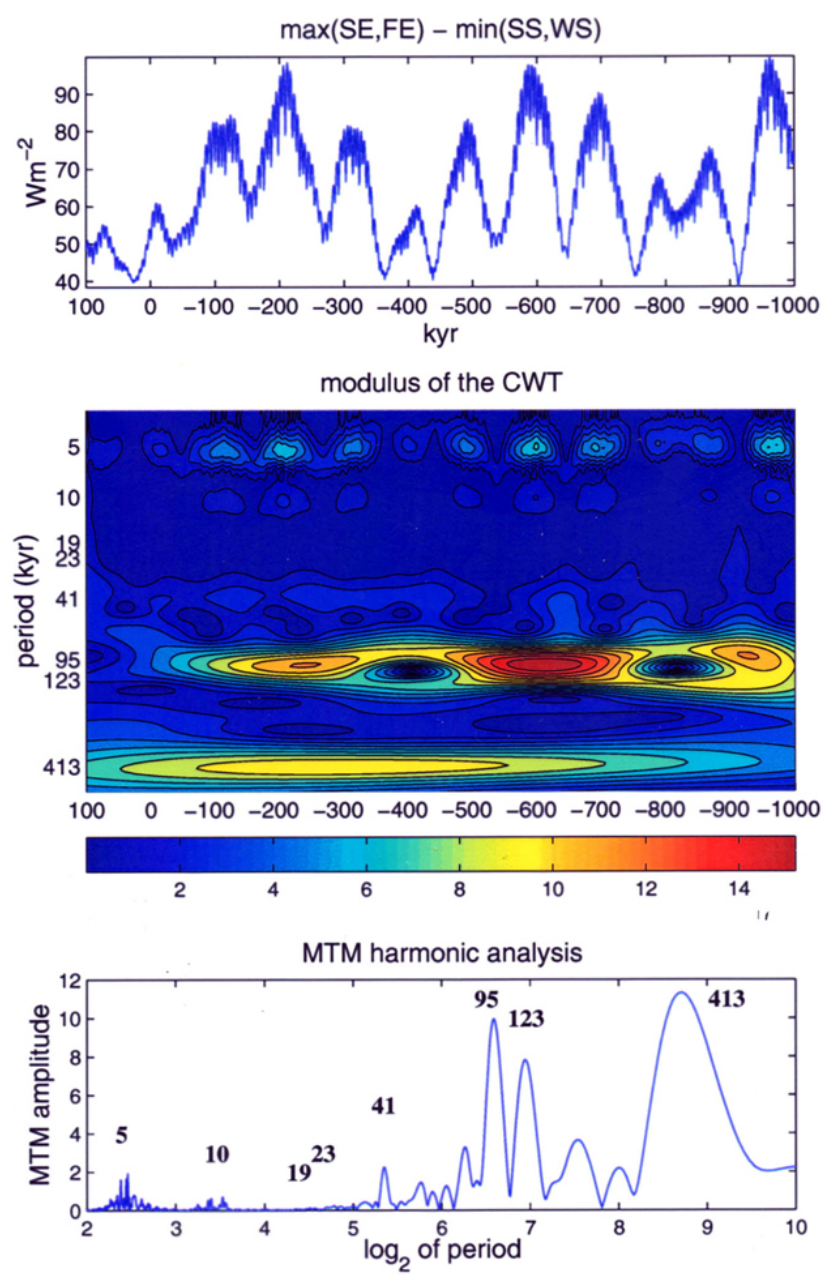

Fig. 5. From top to bottom: (top) time evolution between $1000 \mathrm{kyr}$ $\mathrm{BP}$ and $100 \mathrm{kyr}$ AP of the maximum of the amplitude of the seasonal cycle of the 24-h mean irradiance at the equator, (centre) the modulus of the wavelet transform of the signal on top, (bottom) amplitude in the multi taper analysis of the signal on top.

also be noted that local minima of this index (e.g. $86 \mathrm{Wm}^{-2}$ at $198 \mathrm{kyr}$ BP) might be much larger than local maxima (e.g. $66 \mathrm{Wm}^{-2}$ at $154 \mathrm{kyr} \mathrm{BP}$ ). This is related to the $400-\mathrm{kyr}$ cycle of eccentricity which modulates the amplitude of this seasonal index. The signal of obliquity, which comes from SS and WS is actually weak compared to the harmonics of precession because $\varepsilon$ is not a purely periodic function, but instead is equal to a constant plus a series of periodic terms, the most important having a period of $41 \mathrm{kyr}$. Therefore $\cos \varepsilon$ can be considered as a constant to the first order of approximation.

As all values at the equinoxes and solstices are principally a function of precession, their amplitude is modulated by eccentricity (which is therefore the envelope of insolation). Therefore, through the procedure of the maximum and minimum selection, this envelope becomes naturally the carrier of the "seasonal" contrast of insolation at the equator leading to the existence of eccentricity in the spectra.

As a consequence, the spectrum of $\Delta$ shows the 400,123, $95,41, \sim 10$ and $\sim 5$-kyr quasi-periods, all being significant, especially those of $\sim 100$ and $\sim 5$-kyr (Fig. 5 middle and lower panels). The characteristics of their behaviour are the same as those of eccentricity and precession discussed in Berger et al. (1998).

As this double culmination of the Sun at the zenith is true for the whole intertropical belt, it is interesting to see if this equatorial feature holds for all the other intertropical latitudes. Actually, the spectra for these latitudes continue to show all the frequencies but the amplitude of the 123, 95, 11 and $5.5 \mathrm{kyr}$-cycles decreases rapidly when getting away from the equator. For example, at $5^{\circ} \mathrm{N}$, the largest spectral amplitude is related to precession, followed by eccentricity, then the obliquity and the $11 \mathrm{kyr}$. The harmonic $5.5 \mathrm{kyr}$ is still present but its amplitude is 10 times less than the amplitude of the 11-kyr harmonic.

\section{Conclusions}

One of the questions which might be raised is how this result can help paleoclimatologists in their research. It is true that climate changes at the geological time scale cannot be understood by looking at orbital forcing only. Instead, as already stated by Milankovitch, insolation forcing is only one step in an astronomical theory of paleoclimate. How forcing is transferred to climate (i.e. climate modelling, including climate feedbacks, land-sea distribution and many other processes); how past climates evolved (i.e. data compiling) and how modelled and reconstructed past climates compare each others, are other fundamental steps of paleoclimate studies. However, in this paper, we wanted to focus only on one of these points, i.e. the insolation forcing. More precisely, we want to insist, once again, that in addition to the well-known daily insolation, many other types of insolation parameters might be candidates for explaining climatic records. It is hoped that our mathematical demonstration of the existence at the equator and, to a lesser extend, in the whole intertropical region of the eccentricity, precession and some harmonic periods will tempt the modelers to test this hypothesis.

Clearly, the tropics which cover half of the world play a major role in the climate system. The energy gradient between low and high latitudes which fuels the general circulation in the atmosphere and ocean implies that the dynamics of glacial-interglacial cycles cannot be understood without the tropics. But whether the tropics or the high latitudes are the key for triggering the glacials and the intergklacials cannot be understood by looking at orbital forcing only. Instead, models of the natural Earth system are needed to understand the climate processes and feedbacks. In particular, by using an Earth system model of intermediate complexity, Claussen et al. (2006) showed that an atmosphere-ocean-vegetation 
model in which inland ice masses and greenhouse gas concentrations are kept constant, yields a clear response to climatic precession. If only atmosphere and ocean are coupled, then the amplitude of global mean temperature at climatic precession is reduced, and the eccentricity dominates the temperature variability. The reason for that behaviour is - in their model - a response of the meridional overturning circulation which mediates the impact of the climatic precession at high latitudes in the global mean.

On the other hand, field paleoclimatologists might attempt to look for these short periods in their intertropical geological records. Some of them are already questioning whether the origin of the glacial-interglacial cycles lies only in the high latitudes. They show some evidence that the low latitudes are maybe as or more important than the high latitudes. McIntyre and Molfino (1996) suggested from spectra of high resolution records from the equatorial Atlantic spanning the last $50 \mathrm{kyr}$, that climatic changes in high polar latitudes may be caused by events that occur in low latitudes. Tropical climate systems such as the low-latitude monsoons are known to be sensitive to the seasonal variability of insolation and coupled transequatorial pressure differences (RossignolStrick et al., 1998; Clemens, 1998; Leuchner and Sirocko, 2003). Peeters et al. (2004) suggested a teleconnection between the monsoon system and the ocean circulation, stressing that the Mozambique and Agulhas currents in the western Indian Ocean could be an efficient carrier of the tropical climate signal to the global scale. Thibault de Garidel-Toron et al. (2005) inferred from high resolution records of seasurface temperature from the Pacific warm pool that the temperature contrast across the equatorial Pacific Ocean might have had a significant influence on the mid-Pleistocene climate transition.

Others suggest that the tropics, particularly for moisture availability, is controlled by precession. Palaeoclimate evidence comes from both South America and Africa (de Menocal, 1995, 2004; Maslin et al., 2000; Bush et al., 2002; Trauth et al., 2003; Clement et al., 2004; Cruz et al., 2005) as well as strong evidence from the Mediterranean and Indian Ocean for precessional control over monsoon (e.g., Clemens et al., 1991).

But why are the precession cycles found in the tropics and not the $11 \mathrm{kyr}$ and the $5.5 \mathrm{kyr}$. Is it because we are only focussing on the cycles close to $21 \mathrm{kyr}$ and not looking for the harmonics? Or is it that the moisture at the tropics is controlled by shifting in the monsoon which is ultimately controlled by the sub-tropics which are dominated by the full precessional mode (Ruddiman, 2006). There are however some relevant papers where these harmonics of precession were claimed to be found. For example, Hagelberg et al. (1994) found climate variability at periods from 10 to $12 \mathrm{kyr}$ in three locations for the late Pleistocene. They concluded that this variability may derive from high sensitivity of the tropics to summer time insolation in both hemispheres. An amplified response of tropical precipitation and tempera- ture may then be transmitted to high latitudes in the Atlantic via advective transport, a mechanism appearing consistent with their observations. However, the cycles between 1012 kyr could be very miss-leading as they could be recording the time-transgressive Heinrich events.

Transient simulations with a coupled atmosphere/ocean/vegetation model of intermediate complexity (CLIMBER-2) (Tuenter et al., 2006) found variations at sub-Milankovitch periods of about $10 \mathrm{kyr}$ (Asia and Africa) and about $5 \mathrm{kyr}$ (Asia) in the monsoonal runoff caused by the dynamic response of the vegetation. These sub-Milankovitch periods were identified neither in temperature nor in precipitation.

Turney et al. (2004) found semi-precessional periods and suggested that climate variations in the tropical Pacific Ocean exerted an influence on North Atlantic climate through atmospheric and oceanic teleconnections. The Lake Naivasha record of Trauth et al. (2003) demonstrates that periods of increased humidity in East Africa mainly followed maximum equatorial solar radiation in March or September Another very significant proof of the existence of half-precessional cycles comes from the Chinese loess. According to Sun and Huang (2006), the well-defined half-precessional cycle found in magnetic susceptibility and particle size records from the north western Loess Plateau in China is a direct response of the low-latitude insolation forcing through its modulation on the East Asian Summer monsoon. It might be expected that, if resolution permits, the 5.5-kyr cycle should be found and used as a relevant test of the real role played by the tropics.

These are a few examples only and more must be made to show that indeed the tropics can play a leading role in generating long-term climatic variations. In this paper we have demonstrated that the spectrum of the insolation forcing at the equator is as informative as in the high polar latitudes where only the precession and obliquity signals are present. The double insolation maximum and minimum arising in the tropical regions in the course of one year, which is at the origin of the 100 and $5.5 \mathrm{kyr}$ cycles might explain some of the important features of the climate system and environment over the Pleistocene and the Holocene, like it is suggested also by Lorenz et al. (2006) and Reuning et al. (2006) for example.

Edited by: G. M. Ganssen 


\section{References}

Bard, E. and Frank, M.: Climate change and solar variability, What is new under the Sun, Earth Planet. Sci. Lett., 248, 280-298, 2006.

Berger, A.: Long-term variations of daily insolation and Quaternary climatic changes, J. Atmos. Sci., 35(12), 2362-2367, 1978.

Berger, A., Loutre, M. F., and Tricot, Ch.: Insolation and Earth's orbital periods, J. Geophys. Res., 98(D6), 10341-10362, 1993.

Berger, A. and Loutre, M. F.: Intertropical latitudes and precessional and half-precessional cycles, Science, 278(5342), 14761478, 1997.

Berger, A., Loutre, M. F., and Mélice, J. L.: Instability of the astronomical periods from 1.5 Myr BP to 0.5 Myr AP, Palaeoclimates, Data and Modelling, 2(4), 239-280, 1998.

Bush, M. B., Moreno, E., de Oliveira, P. E., and Colinvaux, P. A.: Orbital-forcing signal in sediments of two Amazonian lakes, J. Paleolim., 27, 341-352, 2002.

Claussen, M., Fohlmeister, J., Ganopolsky, A., and Brovkin, V.: Vegetation dynamics amplifies precessional forcing, Geophysical Research Letters, 33(9), L09709; doi:10.1029/2006GL0266111, 2006.

Clemens, S., Prell, W., Murray, D., Shimmield, G., and Weedon, G.: Forcing mechanisms of the Indian Ocean monsoon, Nature, 353, 720-725, 1991.

Clemens, S.: Dust response to seasonal atmospheric forcing: Proxy evaluation and calibration, Paleoceanography, 13, 471490, 1998.

Clement, A. C., Hall, A., and Broccoli, A. J.: The importance of precessional signals in the tropical climate, Clim. Dyn., 22, 327341,2004

Cruz Jr., F. W., Burns, S. J., Karmann, I., Sharp, W. D., Vuille, M., Cardoso, A. O., Ferrari, J. A., Silva Dias, P. L., and Viana, O.: Insolation-driven changes in atmospheric circulation over the past 116,000 years in subtropical Brazil, Nature, 434, 63-66, 2005.

de Garidel-Thoron, Th., Rosenthal, Y., Bassinot, F., and Beaufort, L.: Stable sea surface temperatures in the Western Pacific warm pool over the past 1.75 million years, Nature, 433(7023), 294298, 2005

deMenocal, P.: Plio-Pleistocene African Climate, Science, 270, 5359, 1995.

deMenocal, P.: African climate change and faunal evolution during the Pliocene-Pleistocene, Earth Planet. Sci. Lett., 220, 3-24, 2004.

Fröhlich, C. and Lean, J.: Solar radiative output and its variability: evidence and mechanisms, Astron. Astrophys. Rev., 12, $273-$ 320,2004

Hagelberg, T. K., Bond, G., and de Menocal, P.: Milankovitch band forcing of sub-Milankovitch climate variability during the Pleistocene, Paleoceanography, 9(4), 545-558, 1994.

Hays, J. D., Imbrie, J., and Shackleton, N. J.: Variations in the Earth's orbit: pacemaker of the Ice Ages, Science, 194, 11211132, 1976.

Kerr, R. A.: The Tropics return to the climate system, Sciences, 292(5517), 660-661, 2001.

Kerr, R. A.: Tropical Pacific a key to deglaciation, Science, 299(5604), 183-184, 2003.

Leuschner, D. C. and Sirocko, F.: Orbital insolation forcing of the Indian Monsoon - a motor for global climate changes?, Palaeo- geography, Palaeoclimatology, Palaeoecology, 197(1-2), 83-95, 2003.

Lorenz, S. J., Kim, J. H., Rimbu, N., Schneider, R. R., and Lohmann, G.: Orbitally driven insolation forcing on Holocene climate trends: evidence from alkenone data and climate modelling, Paleoceanography, 21, PA1002, doi:10.1029/2005PA001152, 2006.

Maslin, M. A. and Burns, S. J.: Reconstruction of the Amazon Basin effective moisture availability over the last 14,000 years, Science, 290, 2285-2287, 2000.

McIntyre, A. and Molfino, B.: Forcing of Atlantic equatorial and subpolar millennial cycles by precession, Science, 274(5294), 1867-1870, 1996.

Milankovitch, M.: Kanon der Erdbestrahlung und seine Anwendung auf das Eiszeitenproblem, Royal Serbian Sciences, Spec. pub. 132, section of Mathematical and Natural Sciences, vol. 33, pp. 633, Belgrade, 1941; ("Canon of Insolation and the Ice Age problem”, English Translation by Israël Program for Scientific Translation and published for the U.S. Department of Commerce and the National Science Foundation, Washington D.C., 1969, and by Zavod za Udžbenike i Nastavna Sredstva in cooperation with Muzej nauke i tehnike Srpske akademije nauka i umetnosti, Beograd, 1998).

Murphy, J. J.: The glacial climate and the polar ice-cap, Quarterly Journal Geological Society, 32, 400-406, 1876.

PMIP2: http://www-lsce.cea.fr/pmip2/.

Peeters, F. J. C., Acheson, R., Brummer, G. J. A., de Ruijter, W. P. M., Schneider, R. R., Ganssen, G. M., Ufkes, E., and Kroon, D.: Vigorous exchange between the Indian and Atlantic ocean at the end of the past five glacial periods, Nature, 430(7000), 661-665, 2004.

Reuning, L., Reijmer, J. J. G., Betzler, Ch., Timmermann, A., and Steph, S.: Sub-Milankovitch cycles in periplatform carbonates from the early Pliocene Great Bahama Bank, Paleoceanography, 21, PA1017, doi:10.1029/2004PA001075, 2006.

Rossignol-Strick, M., Paterne, M., Bassinot, F. C., Emeis, K.-C., and de Lange, G. J.: An unusual mid-Pleistocene monsoon period over Africa and Asia, Nature, 392, 269-272, 1998.

Ruddiman, W. F.: What ist he timing of orbital-scale monsoon changes?, Quaternary Science Review, 25(7-8), 657-658, 2006.

Solanki, S. K., Usoskin, I. G., Kromer, B., Schüssler, M., and Beer, J.: Unusual activity of the Sun during recent decades compared to the previous 11,000 year, Nature, 431, 1084-1087, doi:10.1038/nature02995, 2004.

Sun, J. and Huang, X.: Half-precession cycles recorded in Chinese loess: response to low-latitude insolation forcing during the Last Interglaciation, Quaternary Science Reviews, 25(9-10), 10651972, 2006.

Trauth, M. H., Deino, A., Bergner, A. G. N., and Strecker, M. R.: East African climate change and orbital forcing during the last 175 kyr BP, Earth Planet. Sci. Lett., 206, 297-313, 2003.

Tuenter, E., Weber, S. L., Hilgen, F. J., and Lourens, L. J.: Simulating sub-Milankovitch climate variations associated with vegetation dynamics, Clim. Past Discuss., 2, 745-769, 2006, http://www.clim-past-discuss.net/2/745/2006/.

Turney, C. S. M., Kershaw, A. P., Clemens, S. C., Branch, N., Moss, P. T., and Fifield, L. K.: Millennial and orbital variations of El Niño/Southern oscillation and high-latitude climate in the last glacial period, Nature, 428(6980), 306-310, 2004. 